\title{
Inflammatory demyelinating polyneuropathy in a haemophiliac associated with human immunodeficiency virus infection, responding to high dose intravenous immunoglobulin
}

\author{
R. Panicker, ${ }^{1}$ A.L. Bloom ${ }^{1}$ and D.A.S. Compston ${ }^{2}$ \\ Departments of ${ }^{1}$ Haematology and ${ }^{2}$ Neurology, University Hospital of Wales, Heath Park, Cardiff \\ CF4 $4 X N$, UK.
}

\begin{abstract}
Summary: We describe what we believe to be the first case of chronic inflammatory demyelinating polyneuropathy (CIDP) occurring in a haemophiliac infected with the human immunodeficiency virus (HIV), and the first patient to show a clinical response to treatment with high dose i.v. immunoglobulin. A 55 year old, severe haemophiliac, known to be positive for HIV antibody, presented with a short history of motor weakness and variable sensory loss in both lower limbs. Clinical examination, electrophysiology and sural nerve biopsy confirmed a diagnosis of CIDP. He was treated with a 4-day course of high dose i.v. immunoglobulin, given as a daily infusion. This resulted in dramatic improvement in his neurological status which was evident both clinically and functionally. We conclude that CIDP can occur in HIV-positive haemophiliacs as it does in homosexuals and drug abusers infected with the virus. We also suggest that high dose i.v. immunoglobulin may be effective in the treatment of this condition, especially when practical difficulties preclude the use of plasmapheresis and the use of immunosuppressive drugs is considered hazardous.
\end{abstract}

\section{Introduction}

Chronic inflammatory demyelinating polyneuropathy (CIDP) is a recognized complication of infection with human immunodeficiency virus (HIV), but has not been described in HIV-positive haemophiliacs. ${ }^{1-4}$ Patients with HIV-associated CIDP may respond to therapy with plasma exchange or prednisolone, administered in the belief that idiopathic CIDP has an autoimmune pathogenesis. ${ }^{1-3}$ However, the effect of high dose i.v. immunoglobulin (i.v. IgG) has not been described. We report the occurrence of CIDP in a haemophiliac infected with HIV, who responded clinically to high dose i.v. IgG.

\section{Case report}

A 55 year old white man with severe haemophilia A was noted to be positive for anti-HIV antibody in

Correspondence: Professor A.L. Bloom, M.D.,

1984. In August 1987 he presented with a 3-week history of weakness and paraesthesiae in both lower limbs. Examination revealed flaccid weakness of the legs, absent deep tendon reflexes, flexor plantar responses and variable sensory loss below both mid calves. He had suffered a small left-sided stroke in childhood, causing a long standing mild weakness and brisk tendon reflexes in his left upper limb. Examination was otherwise negative, apart from limitation of joint movement due to previous haemarthroses.

Full blood count showed haemoglobin $13.6 \mathrm{~g} / \mathrm{dl}$, white cell count $3.6 \times 10^{9} / 1$, neutrophils $1.4 \times 10^{9} / 1$ (normal $2.0-7.0 \times 10^{9} / 1$ ) and platelets $191 \times 10^{9} / 1$. The T4:T8 ratio was $0.16 \times 10^{9} / 1: 0.4 \times 10^{9} / 1$ (normal, T4 $0.40-2.2 \times 10^{9} / 1$, T8 $0.2-1.5 \times 10^{9} / 1$ ).

The first cerebrospinal fluid (CSF) examination revealed an elevated protein level $(2.9 \mathrm{~g} / \mathrm{l})$, but a cell count could not be obtained. Subsequent CSF examination confirmed the raised protein and also showed pleocytosis of $26 \times 10^{6} / 1 \quad(90 \%$ lymphocytes), the significance of which was somewhat obscured by the fact that the second lumbar punc-

(C) The Fellowship of Postgraduate Medicine, 1988 
ture was performed 2 weeks after myelography. Bacterial and fungal cultures of CSF were negative and blood serology failed to reveal any evidence of infection with toxoplasma, cytomegalovirus or herpes simplex virus. Antibody to HIV was positive in the serum. The CSF was negative for HIV antigen and antibody. Mild indentations in the L4/ L5 region were shown by myelography but there was no obstruction to the flow of contrast.

Aggressive physiotherapy, with factor VIII cover, resulted in modest, subjective improvement in motor power. Six weeks later he developed numbness on the abdomen and fingertips, increasing motor weakness and inability to walk without support. Neurological examination did not reveal any new physical signs.

CSF examination at this stage showed an elevated protein $(2.8 \mathrm{~g} / \mathrm{l})$ with lymphocytes $6 \times 10^{6} / 1$. Computed tomographic scan showed a low density abnormality consistent with an old right-sided parietal infarct. Nerve conduction studies demonstrated slowed motor and sensory conduction, findings suggestive of a mixed demyelinating polyneuropathy. Sural nerve biopsy under factor VIII cover, showed features of an inflammatory polyneuropathy with myelin loss. In the absence of a family history or evidence for any other underlying cause for his neuropathy, a diagnosis of CIDP associated with HIV infection was made.

There was no useful clinical improvement after a further 6 weeks during which he had physiotherapy but no other treatment. Prednisolone was considered inappropriate in view of his neutropenia and practical difficulties precluded the use of plasmapheresis. The patient was therefore treated with high dose immunoglobulin (i.v. IgG) in a dose of $0.3 \mathrm{~g} / \mathrm{kg}$ body weight daily, given as a slow i.v. infusion. Treatment had been planned for 5 days but was terminated after 4 days because of infection at the nerve biopsy site; this responded with antibiotics. Clinical improvement in motor power was noticeable towards the end of i.v. IgG treatment and within 1 week he was able to walk with minimal support. At this stage his right knee jerk returned to normal and the paraesthesiae on his

\section{References}

1. Cornblath, D.R., McArthur, J.C., Kennedy, P.G. et al. Inflammatory demyelinating polyneuropathies associated with human T-cell lymphotropic virus type III infection. Ann Neurol 1987, 21: 32-40.

2. Levy, R.M., Bredesen, D.E. \& Rosenblum, M.L. Neurological manifestations of the acquired immunodeficiency syndrome (AIDS): experience at UCSF and review of the literature. J Neurosurg 1985, 62: 475-495.

3. Lipkin, W.I., Parry, G. Kiprov, D. et al. Inflammatory neuropathy in homosexual men with lymphadenopathy. Neurology 1985, 35: 1479-1483. abdomen resolved completely. There was no deterioration in his neurological status over the next 6 months.

\section{Discussion}

Chronic inflammatory demyelinating polyneuropathy is known to occur, in the absence of other causes, in homosexuals, drug abusers and asymptomatic patients infected with HIV. ${ }^{1-4}$ It presents with progressive motor weakness, variable sensory loss, raised CSF protein, CSF pleocytosis, slowing of nerve conduction velocities and histological evidence of peripheral nerve inflammation and demyelination. Our patient showed all these features, but is unique in that CIDP developed in a haemophiliac infected with HIV. Response to therapy with prednisolone or plasmapheresis has previously led investigators to suggest that, as in cases of idiopathic CIDP, the pathogenesis of this condition is related to disordered immune regulation; direct neuronal infection with HIV, though possible, is unlikely to be the primary mechanism. ${ }^{1}$ In our patient, prednisolone was considered inappropriate since he was already immunosuppressed and practi cal difficulties precluded the use of plasmapheresis?

High dose i.v. immunoglobulin has been use successfully in several diseases associated with altered immunity such as immune thrombocytopenic purpura. ${ }^{5}$ For this reason we treated our patient with a 4-day course of i.v. IgG. The improvement was clinically useful although the sensory deficit showed only partial improvement. High dose i.v. IgG has been reported to predispose to pyogenic infection (Paper read at meeting of British Society of Immunology, London 1987), and for this reason we terminated therapy on the fourth day.

We conclude that high dose i.v. IgG may be useful in the mangement of patients with CIDP associated with HIV infection, in whom more conventional treatment is practically difficult. However, studies on other patients are required to assess its efficacy in more detail.

4. Gabuzda, D.H. \& Hirsch, M.S. Neurologic manifestations of infection with human immunodeficiency virus. Ann Intern Med 1987, 107: 383-391.

5. Haas, A. Use of intravenous immunoglobulin in immunoregulatory disorders. In: Stiehm, E.R., moderator. Intravenous Immunoglobulin as the Therapeutic Agents. Ann Intern Med 1987, 107: 367-382. 